\title{
Técnicas de gamificação em plataforma Moodle aplicadas a um curso sobre solução de conflitos
}

Moodle platform gamification techniques applied to a conflict resolution course

KAWAGOE, Akemi Leandra; Mestranda; Universidade de Brasília (UnB)

akemikawagoe@gmail.com

MEDEIROS, Daniel Nascimento; Especialista; Universidade de Brasília (UnB)

daniel.medeiros@embrapa.br

CHULES, Magali Regina Kolakowski; Especialista; Universidade de Brasília (UnB)

magali.chules@gmail.com

FRAGELLI, Ricardo Ramos; PhD; Universidade de Brasília (UnB)

fragelli@unb.br

SILVA, Wander Cleber Maria Pereira da; PhD; Universidade de Brasília (UnB)

wandercleber@gmail.com

SILVA, Tiago Barros Pontes e; PhD; Universidade de Brasília (UnB)

tiagobarros@unb.br

\section{Resumo}

O presente estudo consiste em analisar as possibilidades de gamificação de uma experiência de aprendizagem, empregando ferramentas livres, usáveis e úteis para educadores que não dominem ferramentas de programação. Para tanto, o processo de desenvolvimento da gamificação seguiu etapas orientadoras de desenvolvimento de ações de aprendizagem, ferramentas, metodologias e frameworks de planejamento e gamificação. Assim, todos os plug-ins relacionados à adaptação e gamificação disponíveis no diretório de plug-ins do site oficial da plataforma Moodle foram avaliados com base no framework Octalysis. Também são apresentados exemplos de uso das técnicas e drives da Octalysis a partir da implementação de determinados plug-ins.

Palavras Chave: educação; EaD; gamificação e Moodle.

\section{Abstract}

The present study aims to investigate the possibilities of gamification of a learning experience, using free, usable and useful tools for educators whom do not master programming tools. In this sense, the process of development of the gamification followed the development of learning actions, tools, methodologies and frameworks of planning and gamification. Thus, all the plug-ins related to adaptation and gamification available in the plug-in directory of the official site of the Moodle platform were evaluated according to the Octalysis framework. Examples of the implementation of the Octalysis techniques and drives of certain plug-ins are also presented.

Keywords: education; distance education; gamification and Moodle. 


\section{Introdução}

As ações educacionais na modalidade a distância se expandem com o desenvolvimento e a democratização do acesso às Tecnologias Digitais de Comunicação e Interação - TDICs. Entre outras influências, acredita-se que esse crescimento seja potencializado pelas vantagens dessa modalidade educacional, como a flexibilização do tempo, ritmo e local de aprendizagem aliado às possibilidades midiáticas e a construção compartilhada de conhecimento.

O rápido e constante desenvolvimento das TDICs cria um contexto de mudanças. A partir dessas mudanças surgem novos aprendizes, com desejos e necessidades diferenciados. Assim, nasce a necessidade de propostas educacionais significativas pautadas no uso de múltiplas mídias, metodologias ativas e colaborativas.

Contudo, muitas ações de aprendizagem ofertadas a distância, mesmo em face desse cenário de tantas possibilidades, tentam reproduzir a sala de aula tradicional. De fato, um dos desafios presentes é o de promover os vínculos próprios do encontro presencial, mas sob o olhar deste tempo de mudanças.

Também por essa razão, embora o volume de ações ofertadas a distância tenha crescido vertiginosamente, a modalidade ainda busca resultados melhores tanto nos parâmetros relacionados à aprendizagem quanto no que diz respeito ao engajamento dos estudantes. Um exemplo de metodologia de aprendizagem ativa, lúdica e desafiadora, que considera os motivadores humanos, é a gamificação. A gamificação pressupõe o uso de técnicas de jogos em contextos tradicionalmente não divertidos.

Mas gamificar uma ação educacional pode parecer complexo e inacessível por envolver aspectos metodológicos, assim como tecnológicos. Nesse sentido, e olhando do ponto de vista dos educadores, este trabalho busca, a partir da análise de possibilidades de gamificação de uma experiência de aprendizagem considerando o framework Octalysis e a plataforma Moodle, se aproximar de respostas para as questões: que técnicas de gamificação referidas no Octalysis são possíveis usando plataforma Moodle e seus plug-ins? Como um educador que não programa poderia gamificar cursos usando plataforma Moodle?

Para aplicação das técnicas de gamificação foi estabelecido um tema e foram estruturados alguns conteúdos no Moodle para simular dinâmicas que poderiam ocorrer na gamificação. Batizado de "A paz em nós - para um mundo mais humano", o curso representado aborda a temática da solução de conflitos. Seu objetivo educacional é o desenvolvimento de competências para prevenir, compreender e solucionar contenciosos por meio de empatia, compreensão e mediação para a promoção da paz e da justiça. Destaca-se que o foco do presente relato consiste na análise das possibilidades de gamificação, não abordando o conteúdo do curso sobre resolução de conflitos propriamente dito.

Entende-se que o conflito é uma fricção de interesses, própria da complexidade humana, que se acumula nas pessoas na forma de sensações como raiva, injustiça e angústia. Nasce das diferenças ou das necessidades feridas e, uma vez instaurado, pode gerar abismos nas relações e uma sensação perene de injustiça. O tema é considerado relevante porque os conflitos estão presentes historicamente na jornada dos seres humanos, desde desentendimentos cotidianos a conflitos internacionais que geram guerras, crises sociais, terrorismo ou formação de milícias. Embora conflitos sejam inerentes ao convívio humano, a falta de competência e autonomia para 
resolvê-los levam à terceirização das soluções. Na infância, os pais são frequentemente demandados pelos filhos nos casos de conflito. Na escola, professores cumprem esse papel. Na vida adulta, o judiciário é o caminho para a terceirização da solução dos conflitos.

Mas nem sempre a solução dos conflitos por meio do judiciário promove a plena justiça situação na qual as pessoas percebem que a questão foi adequadamente resolvida e que seus anseios foram atendidos. No judiciário, a perspectiva de objetividade da legislação, muitas vezes, impede o Juiz de enxergar o ser humano na sua totalidade e, em geral, existe a hipótese de um perdedor para as causas apreciadas.

O que pode ser chamado de solução parcial dos dissensos tem potencial gerador de novas controvérsias porque as partes não se sentem atendidas. Na mesma direção, as soluções terceirizadas podem carregar o viés da legislação (que não necessariamente é justiça) e levar anos para se resolver. Portanto, entende-se que o conflito pode ser um instrumento para fomentar transformações e dele pode nascer um novo jeito de coexistir, desde que seja possível lidar com o conflito na perspectiva do desenvolvimento humano, gerando relações mais duradouras e equilibradas.

Para tanto, o objetivo do presente estudo consiste em analisar as possibilidades de gamificação de uma experiência de aprendizagem, empregando ferramentas livres, usáveis e úteis para educadores que não programem computadores. Para apoiar os educadores no desenho de experiências gamificadas com o Moodle, pretende-se:

- Analisar os motivadores de gamificação Octalysis visando a sua adequação aos objetivos de aprendizagem da ação educacional simulada;

- Analisar os plug-ins sob a ótica dos motivadores e técnicas do framework de gamificação Octalysis;

- Aplicar algumas das funcionalidades, plug-ins e drives do Octalysis para a gamificação de uma ação de aprendizagem a distância simulada.

\section{Referencial teórico}

Muitas atividades pedagógicas em Educação a Distância (EaD) ainda se pautam em metodologias passivas enquanto os estudantes convivem cotidianamente com o dinamismo das mídias digitais. Segundo Fragelli (FRAGELLI, 2012), metodologias ativas têm apresentado resultados melhores quando comparadas às metodologias passivas. Uma das razões é que as metodologias ativas elevam o aprendiz à posição de protagonista no processo de aprendizagem e esse é um componente relevante para mantê-lo motivado.

Moran (2015) vê as metodologias ativas como o caminho para transformar a prática pedagógica tradicional em uma educação mais flexível, centrada nas necessidades e expectativas dos aprendizes. Propostas educacionais nessa linha focam no aprender fazendo, na resolução de problemas reais, apoiando os aprendizes na integração de conhecimentos amplos, valores, projeto de vida, por meio de desafios relevantes, jogos, atividades, leituras individuais e em grupo.

Berbel (2011) afirma que metodologias ativas são novas formas de aprender, partindo de experiências reais ou simuladas, que propiciam o engajamento e o interesse do aprendiz pela possibilidade de exercitar liberdade e autonomia para tomar decisões no processo que vivencia. $E$ o potencial dessas metodologias está em aguçar a curiosidade, na medida em que os alunos 
tomam contato com a teoria e trazem elementos novos, diferentes dos considerados pelo professor na construção da ação de aprendizagem. Com isso, quando esses elementos são adotados, analisados e valorizados, promovem nos alunos sentimentos de pertencimento, percepção de competência, desejo de persistir, o que impacta em seu engajamento.

Essa perspectiva corrobora a visão de Paulo Freire (1996), que aborda a necessidade de uma educação que incentive o potencial criativo, leve o educando a superar desafios, resolver problemas e seja comprometida com a formação da consciência crítica.

Desafios e atividades mediadas por tecnologia, se bem planejados, contribuem para o desenvolvimento de competências diversas como: intelectuais, pessoais, emocionais e comunicacionais, uma vez que requerem do aprendiz pesquisa, escolha, análise de ponto de vista, assumir riscos, aprender pela descoberta (MORAN, 2015).

Neste contexto, a metodologia de gamificação é considerada uma alternativa viável e motivadora para o alcance de objetivos pedagógicos em ambientes virtuais de aprendizagem, pois tecnologias digitais favorecem planejar atividades interligando objetivos, desafios, narrativas, feedbacks e pontuações, tornando o aprender mais agradável. Além disso, a resolução de problemas pode ser potencializada pela aplicação de estratégias colaborativas e competitivas gamificadas para solução de desafios, estimulando cada participante a se superar.

Ainda, para Prensky (2012), os atributos definidores do jogo são justamente os fatores que tornam o jogar uma experiência engajadora. Mais do que isso, para o autor, são esses os elementos estruturantes que devem ser relacionados ao processo de aprendizagem: o jogar, as regras, metas, interações, adaptações, ações, feedbacks, vitórias, conflitos, resoluções e interpretações são os elementos do jogo que promovem o prazer, envolvimento, estruturação, motivação, realização, estado de fluxo, aprendizagem, criatividade, relações sociais e afetos.

Para o autor, assim como para Ebner e Holzinger (2007), a aprendizagem baseada em jogos pode ser considerada como uma importante ferramenta, pois emprega as ações dos jogadores em vez de uma postura passiva de simples exposição ao conteúdo, além de permitir a criação de motivação e satisfação pessoal nos alunos, reunindo diversos estilos de aprendizagem e competências, fornecendo um contexto interativo para a tomada de decisão, o que evidencia uma adequação às características da atual geração de estudantes, que cresceu com acesso às Tecnologias Digitais de Comunicação e Interação - TDICs. Prensky (2012) afirma que há cada vez menos tolerância da geração dos jogos em situações de aprendizagem passiva, como as salas de aula, palestras, treinamentos corporativos ou reuniões tradicionais.

Assim, a gamificação significa aplicar elementos do jogo em situações, solução de problemas fora do contexto de jogos. Kapp (2012, apud FARDO, 2013) conceitua gamificação como "o uso de mecânicas, estética e pensamentos dos games para envolver pessoas, motivar a ação, promover a aprendizagem e resolver problemas".

Um desafio das metodologias ativas e da gamificação no contexto tecnológico, olhando do ponto de vista do educador, são as competências tecnológicas normalmente exigidas para promover ações engajadoras. Nesse sentido, é relevante o uso de tecnologias com distribuição livre, gratuitas e abertas com interface simplificada, sem necessidade de que o educador tenha competências de desenvolvedores de software.

Este é, portanto, um trabalho de metadesign, na concepção de Vassão (2010), de design do 
design, de criar uma representação da realidade complexa em simplicidades, usando abstrações, ferramentas, esquemas etc.

Durante o processo de desenvolvimento da gamificação, percebeu-se o desafio de usar de forma adequada as técnicas de jogos, agregando os componentes engajadores e relevantes para a ação de aprendizagem. Nesse percurso, foi verificado que é preciso entrar no campo do fascínio pela ludicidade, prazer pela atividade, relevância do problema por si mesmo, sensação de presença, liberdade de escolhas, colaboração implícita entre jogadores no atendimento às regras e no compartilhamento de informações no contexto do jogo (SILVA, 2016).

Para Silva (2016) é necessário aprofundar estudos sobre o processo de desenvolvimento de jogos e a experiência que o jogador vivencia. Desse modo, poderá se alcançar maior compreensão de como o jogo afeta o jogador e como as diversas variáveis se relacionam com as expectativas e habilidades do jogador de forma a conquistá-lo à imersão, bem como sobre a sensação de estar desenvolvendo habilidades e as colocando à prova, ou seja, manifestando a competência.

Contudo, fazer com que o jogo, ou processo gamificado, seja intrinsecamente significativo para as pessoas não é uma tarefa fácil. Visando a compreensão acerca dos fatores que motivam as pessoas a realizarem certas atividades, foi proposta a abordagem denominada Octalysis (Chou, 2014). Ela consiste no levantamento prévio dos fatores relevantes para determinado público que sejam relacionados ao processo gamificado, de maneira que possam ser articulados no momento da sua confecção.

A partir dessa perspectiva, os oito motivadores do Octalysis, propostos pelo framework de Chou (2014), foram direcionadores no desenvolvimento da gamificação. Eles consistem em "Significado Épico e o Chamado"; "Desenvolvimento e realização"; "Fortalecimento da criatividade e feedback"; "Propriedade e possessão"; "Influencia Social e Associações"; "A falta e a impaciência"; "Imprevisibilidade e Curiosidade"; "Perda e Temor". Posteriormente, para cada um dos drives, associados às suas técnicas, foram inventariados, instalados e testados os plug-ins e funcionalidades correspondentes na plataforma Moodle, versão 3.2.

Isso não significa necessariamente que toda gamificação precisa conter todos os motivadores, mas que existem possibilidades de gamificar com o Moodle usando um certo conjunto de drives do framework. A escolha dos drives, no âmbito deste trabalho, está relacionada ao público, aos objetivos educacionais, ao ambiente e aos recursos disponíveis. De todo modo, como um projeto de metadesign a ideia consiste em inventariar as funcionalidades e plug-ins compatíveis com a versão estável do Moodle.

Finalmente, gamificar atividades de um curso sobre solução de conflitos em EaD teve como intenção demonstrar como na educação a distância os aprendizes podem exercitar as competências essenciais para atuarem como mediadores na solução de conflitos, por meio de uma prática pedagógica inovadora.

\section{Metodologia}

O processo de gamificação seguiu etapas orientadoras de desenvolvimento de ações de aprendizagem, ferramentas, metodologias e frameworks de planejamento e gamificação. Além de critérios de usabilidade e de experiência do usuário-educador, próprias do design de interação como proposto por Preece, Rogers e Sharp (2005). 


\subsection{Ideário e Mapa mental}

Por meio de um mapa mental com conceitos e ideias, foram escolhidos: o tema do conteúdo, processos de construção, as tecnologias e abordagens. Essa foi uma etapa relevante no planejamento da experiência, do trabalho porque representa uma visão global dos diálogos da equipe e um método ágil de organizar os pensamentos e contribuições do grupo. Nesse momento, ainda não havia a tomada de decisão entre jogo e gamificação.

O mapa de ideias chegou a abordar uma certa mecânica de jogo, com algumas ideias para a narrativa, mas o amadurecimento do trabalho foi evidenciando possíveis resultados que poderiam ser mais relevantes na experiência (Figura 1).

\section{Figura 1 - Mapa mental sobre o ideário do projeto}

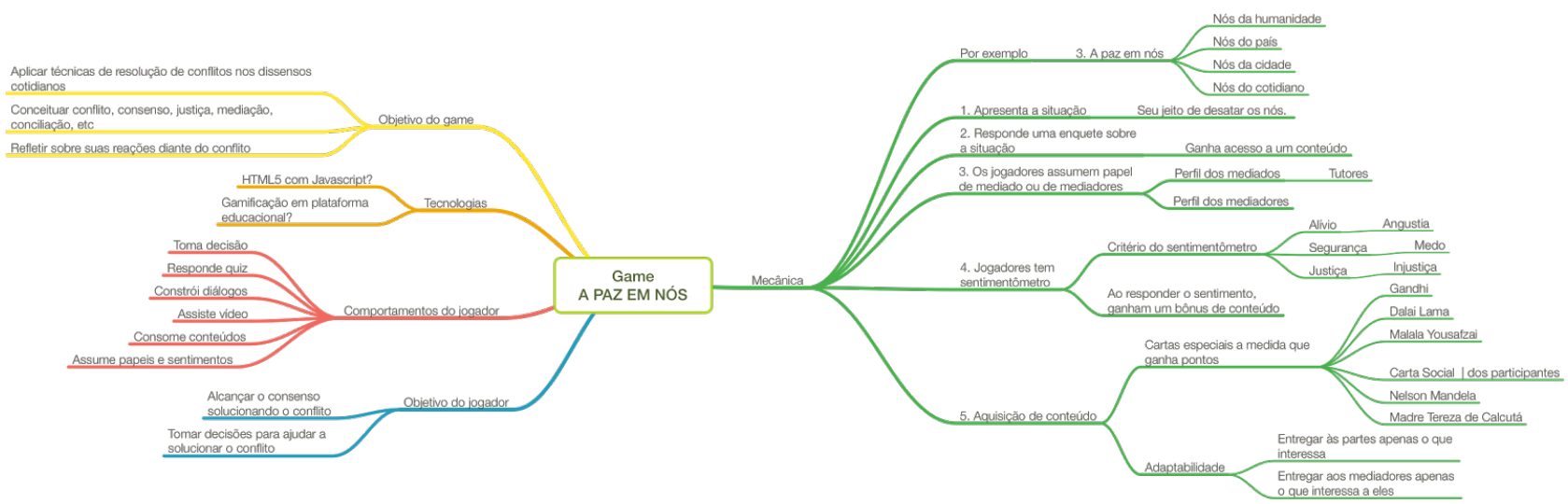

Fonte: o autor

\subsection{Gamification Model Canvas}

O Business Model Canvas é uma metodologia ágil que permite processos sistematizados de planejamento e gestão. Com base no modelo desenvolvido pela GAMEONLAB para gamificação, foi adaptado um Canvas para gamificação de curso a distância (Figura 2).

As principais adaptações foram a inclusão do contexto e necessidade de retirada dos campos de custos, não contabilizado no âmbito deste trabalho - mesmo que pudessem ser considerados custos humanos, de software ou de infraestrutura.

O uso do Canvas parece sobrepor ao framework Octalysis, mas serviu como instrumento para análise de reflexão sobre a dinâmica e mecânica da gamificação. Embora o Canvas tenha sido uma ótima ferramenta para planejamento da gamificação, a pesquisa de referências de plug-ins e experiências de gamificação foi mais inspiradora para a concepção da dinâmica de pontuação do curso. 
Figura 2 - Gamification Model Canvas adaptado para o curso A Paz em Nós

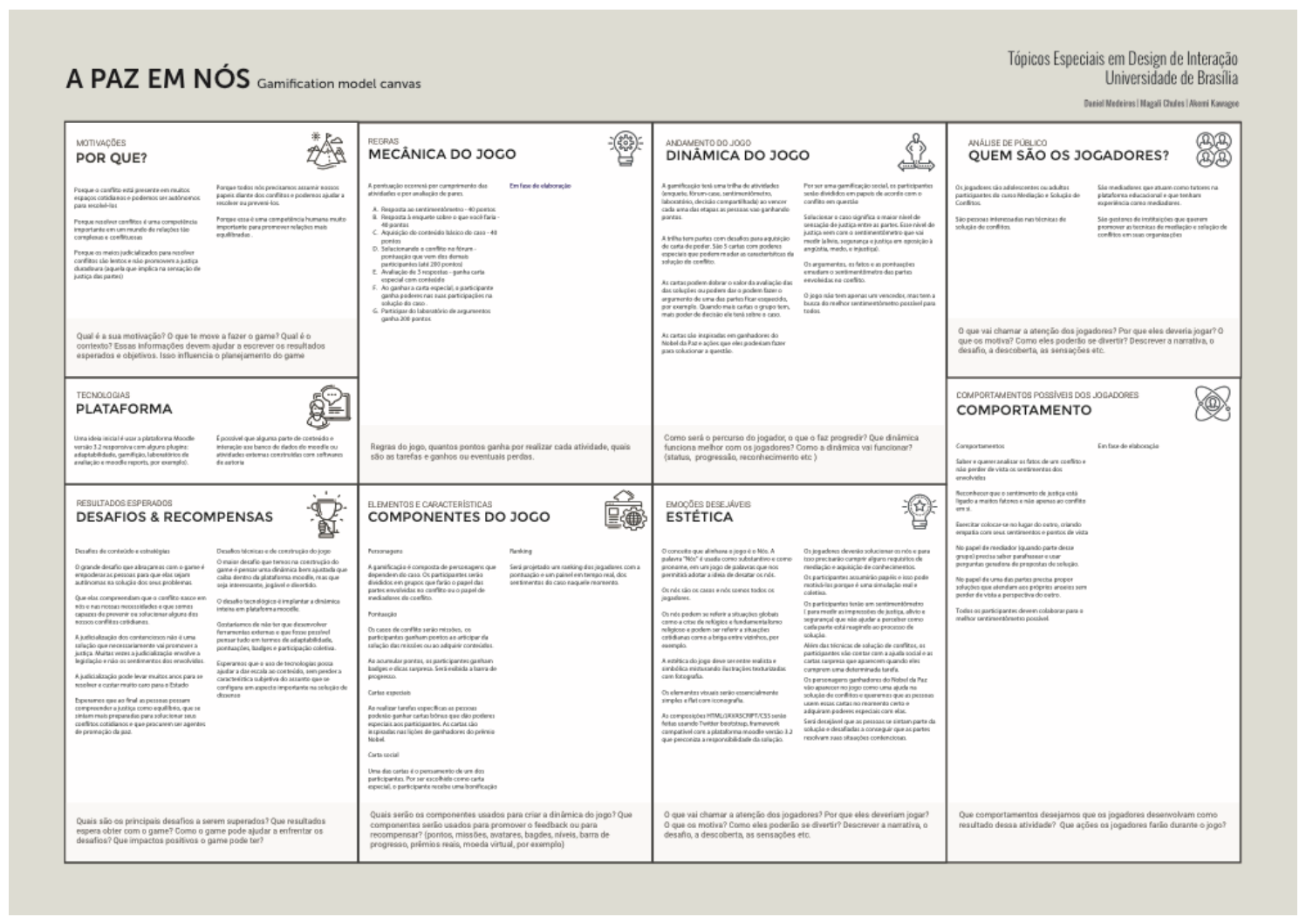

Fonte: o autor

\subsection{Análise e aplicação dos core drives do Octalysis}

A partir do framework idealizado por Yu Kai Chou, foram identificados os drives que poderiam ser adotados na gamificação do curso a Paz em Nós. A restrição da escolha dos drives está nas possibilidades funcionais já disponíveis na plataforma Moodle, de forma que não seja necessário desenvolvimento de novos componentes com uso de programação.

Muito embora haja muitas possibilidades de avanços usando linguagens de programação, é possível explorar diversas dinâmicas com componentes já desenvolvidos. Na Figura 3, representação do framework Octalysis, são apresentados drives e técnicas selecionadas que têm funcionalidade ou plug-in da plataforma Moodle. 
Figura 3 - Drives e técnicas selecionadas que tem funcionalidade ou plug-in da plataforma Moodle

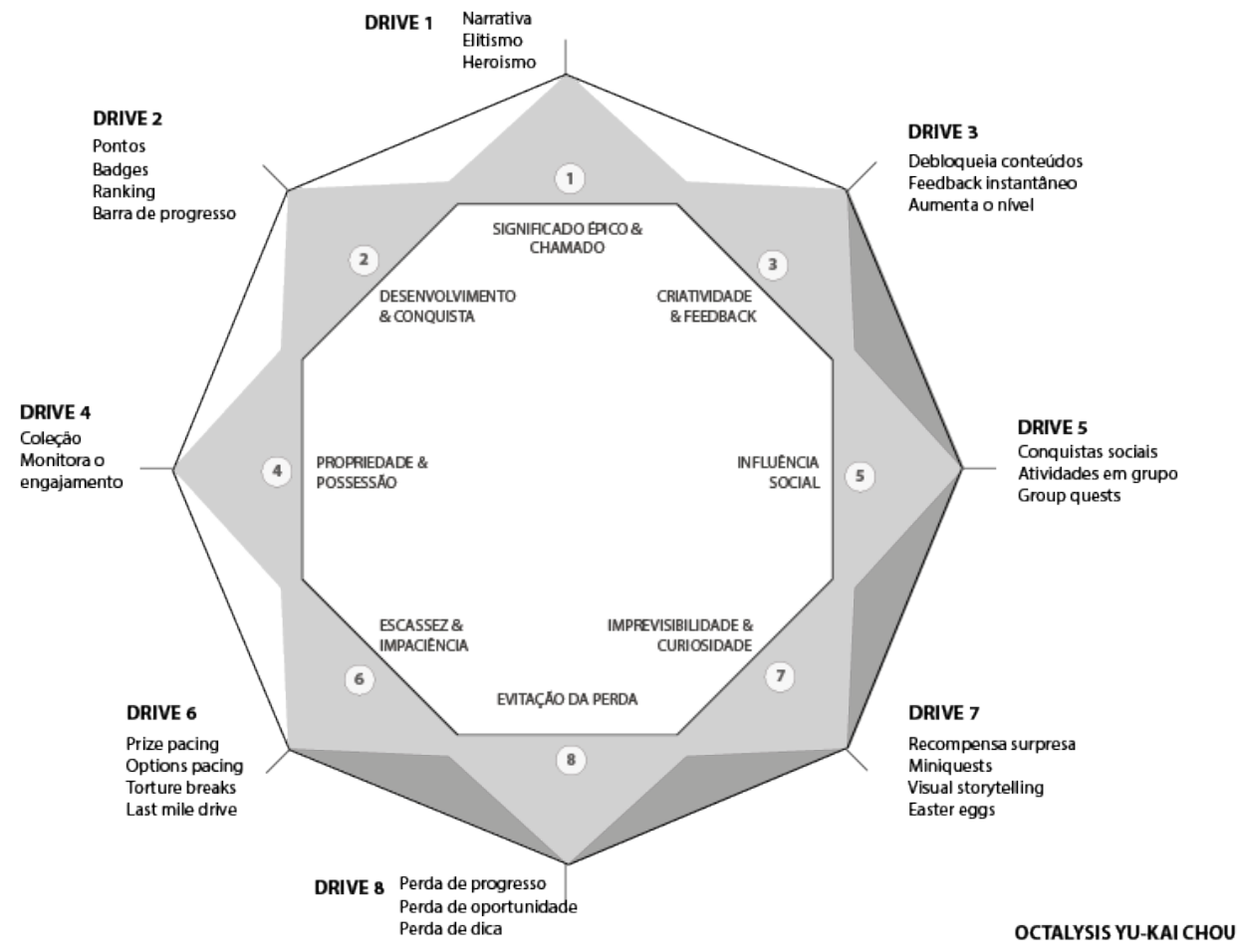

Fonte: o autor

\subsection{Moodle: inventário de plug-ins e funcionalidades nativas}

Foi realizada a instalação da plataforma Moodle versão 3.2 e inventariados os plug-ins compatíveis. De forma complementar ao levantamento de plug-ins, foram feitas pesquisas em artigos, vídeos e sites sobre gamificação com a plataforma Moodle, configurando um benchmarking sobre as experiências de gamificação com essa plataforma.

Todos os plug-ins relacionados à adaptação e gamificação disponíveis no diretório de plugins do site oficial da plataforma Moodle foram avaliados com base no framework Octalysis. Foram selecionados aqueles que apresentavam potencial motivador de acordo com os drives da metodologia e que atendiam aos critérios de usabilidade - eficiente, eficaz, seguro, útil, fácil de aprender e fácil de lembrar de acordo com Preece, Rogers e Sharp (2005).

Na Tabela 1 pode vista a lista de alguns plug-ins selecionados a partir desses critérios e a indicação, com a letra $x$ na primeira coluna, daqueles que foram testados. 
Tabela 1 - Plug-ins selecionados a partir dos critérios de usabilidade propostos por Preece, Rogers e Sharp (2005)

\begin{tabular}{|c|c|c|c|}
\hline & & Plug-ins adicionados & Descrição \\
\hline $\mathrm{X}$ & 01 & Level UP! & Configuração de níveis por pontuação e rankings de níveis \\
\hline $\mathrm{X}$ & 02 & Ranking & Ranking de todas as atividades somadas \\
\hline \multirow[t]{2}{*}{$x$} & 03 & Easter egg (esconderijo) & Configuração de conteúdos escondidos e coleções \\
\hline & 04 & E-voting & Votação por dispositivos mobile em escala \\
\hline \multirow[t]{2}{*}{$\mathrm{X}$} & 05 & Checklist de atividades & Lista de atividades (usamos a lista nativa do Moodle) \\
\hline & 06 & Formato botões & Formatação do curso em modo de botões sequenciais e configuráveis \\
\hline $\mathrm{x}$ & 07 & Quizventure & Criação de um arcade game a partir do banco de perguntas \\
\hline $\mathrm{X}$ & 08 & Forum graph & Visualização das interações que acontecem em fóruns de discussão \\
\hline $\mathrm{X}$ & 09 & Certificado online & Emissão automática de certificações quando cumpridas certas condições \\
\hline \multirow[t]{3}{*}{$\mathrm{X}$} & 10 & Acesso adaptativo & Configuração de critérios de disponibilização e acesso a conteúdos e cursos \\
\hline & 11 & Quiz adaptativo & $\begin{array}{l}\text { Configuração de questionários adaptativos segundo critérios pré- } \\
\text { estabelecidos por nível de complexidade e domínios das questões }\end{array}$ \\
\hline & 12 & Hotpotatoes activities & Inclusão de atividades tipo hotpotatoes com contabilização de pontuações. \\
\hline $\mathrm{x}$ & 13 & Moodle games & Inclusão de games como forca, palavras cruzadas, sudokus como atividades \\
\hline $\mathrm{x}$ & 14 & Reports gráficos & Visualização de relatórios de atividades e controles de progresso por gestores \\
\hline $\mathrm{X}$ & 15 & Conclusão condicional & $\begin{array}{l}\text { Condicionamento da conclusão do curso a certos critérios de acesso, } \\
\text { pontuação ou resultados das avaliações. }\end{array}$ \\
\hline \multirow[t]{2}{*}{$x$} & 16 & Welcome user & Notificação de novos usuários com atividades específicas. \\
\hline & 17 & Mobile Moodle & $\begin{array}{l}\text { Configuração do Moodle como um app personalizável para acesso de todas as } \\
\text { atividades por dispositivo móvel }\end{array}$ \\
\hline $\mathrm{X}$ & 18 & Barra de progresso & Disposição de uma barra de progresso para os usuários \\
\hline
\end{tabular}

Fonte: o autor

\section{Aplicação da gamificação}

Um aspecto interessante da dinâmica do curso é que pensar um curso gamificado é diferente de pensar um curso não gamificado. Possivelmente, pelo modelo de desenho educacional que for adotado, deverá ser feito um balanço do drives e atividades para que não fiquem repetitivos e atendam aos diversos perfis de aprendizagem.

Além disso, para que a dinâmica seja representada de forma mais clara, é importante haver mais dados e mais participantes ou a gamificação, nesse caso, é menos engajadora, pelo modelo e dinâmica que foi adotado. Percebeu-se que as vezes é melhor pensar o conteúdo e o desenho educacional e depois, no processo de produção das mídias, pensar a gamificação. 0 Quadro 1 exemplifica a relação entre as atividades, dinâmicas, plug-ins e drives estabelecidos. 
Quadro 1 - Relação entre as atividades, dinâmicas, plug-ins e drives estabelecidos

\begin{tabular}{|c|c|c|c|}
\hline Atividade & Dinâmica & Plug-in & Drives \\
\hline Conflitos da humanidade & $\begin{array}{l}\text { Apresentação com vídeo e conteúdo } \\
\text { escondido. }\end{array}$ & Youtube & Significado épico \\
\hline Mapa interativo de conflitos & $\begin{array}{l}\text { Conteúdo interativo com conteúdo } \\
\text { escondido }\end{array}$ & HTML & $\begin{array}{l}\text { Supresa e } \\
\text { imprevisibilidade }\end{array}$ \\
\hline $\begin{array}{l}\text { Que conflitos da humanidade } \\
\text { você gostaria de resolver }\end{array}$ & Escolha social do conflito a ser resolvido & Enquete e pontos & Influência social \\
\hline Positivômetro & $\begin{array}{l}\text { Enquete para saber o quão otimista as } \\
\text { pessoas são sobre os conflitos }\end{array}$ & Enquete e pontos & - \\
\hline Solução coletiva de conflitos & $\begin{array}{l}\text { Fórum temático é aberto conforme a } \\
\text { pessoa escolhe um dos temas }\end{array}$ & $\begin{array}{l}\text { Acesso condicional } \\
\text { e pontos }\end{array}$ & $\begin{array}{l}\text { Impaciência e } \\
\text { Conquista }\end{array}$ \\
\hline $\begin{array}{l}\text { Conteúdo de teoria dos } \\
\text { conflitos }\end{array}$ & Conteúdo não finalizados & Easter egg & Imprevisibilidade \\
\hline Caso de conflito cotidiano & Caso de conflito & Easter egg & Imprevisibilidade \\
\hline $\begin{array}{l}\text { Wiki para reconstrução de } \\
\text { diálogos }\end{array}$ & Construção de diálogos compassivos & $\begin{array}{l}\text { Wiki e pontos e } \\
\text { badges }\end{array}$ & Conquista \\
\hline Solução de conflito cotidiano & Fórum da solução & Pontos e badges & Influência social \\
\hline Palavras que ferem & Jogo tipo árcade com questionários & Pontos, Badges & Conquista \\
\hline
\end{tabular}

Fonte: o autor

\subsection{Exemplos de uso das técnicas e drives}

A seguir são apresentados exemplos de uso das técnicas e drives, organizados em significado épico e sensibilização com vídeo, controle de conclusão e lista de atividades, escolha eletrônica e enquetes, níveis globais por pontuação e por grupos, acesso condicional e barra de progresso, emblemas ou badges, conteúdo escondido easter eggs e quizventure.

\subsubsection{Significado Épico e sensibilização com vídeo}

Significado épico ou chamado é o primeiro core drive do framework Octalysis e pode ser ativado por componentes de gamificação que despertem nas pessoas o sentimento de que há na atividade a ser realizada uma causa maior do que elas próprias (CHOU, 2014). Incluir o usuário em um grupo que possui uma missão importante é uma das técnicas deste core drive. Construir uma narrativa que coloque a pessoa em uma jornada heroica ou que expresse uma contribuição social resultante da atividade também são recursos com potencial de motivação.

No tema do curso utilizado como objeto para gamificação, foi utilizado o recurso de vídeo para construir uma narrativa que desperta no usuário uma tomada inicial de consciência sobre conflitos no dia-a-dia e em seguida mostra que ele pode fazer parte de um grupo seleto de pessoas com competências para enxergar e administrar conflitos. Ao final, o vídeo mostra como os conflitos congestionam o judiciário brasileiro e explica que os processos de mediação podem ajudar a resolver conflitos antes mesmo de ser necessário acionar a justiça. 
O vídeo foi o suporte escolhido por facilitar a construção de narrativas de forma rápida e multimídia. Outros formatos, no entanto, podem ser utilizados, como textos, ou jogos. 0 objetivo é despertar na pessoa a consciência de que atuar como mediador pode ter efeitos positivos não apenas para quem está envolvido no conflito, mas para toda uma coletividade na medida em que contribui para acelerar o sistema de justiça nacional. É um chamado para uma ação de cunho humano, social e coletivo.

Assim como acontece em diversos jogos, a construção da narrativa para significado épico no contexto do curso é feita logo no início da interação. O vídeo é apresentado como o primeiro conteúdo do curso estruturado no Moodle. Além de ter como objetivo estabelecer o significado épico, o vídeo busca despertar no usuário curiosidade por descobrir quais são as técnicas que ajudam a evitar, identificar e mediar conflitos.

O significado épico, no Octalysis, faz parte do chamado White Hat, que são core drives que geram motivações positivas. Isto é um elemento importante no contexto da gamificação do curso, uma vez que o objetivo da mediação é a promoção da paz e o restabelecimento dos laços sociais de pessoas envolvidas em conflitos. São ações diretamente ligadas a bondade e a generosidade, 0 que favorece ênfase em core drives positivos. Em se tratando de conteúdos de natureza educativa, core drives positivos são interessantes por associarem a atividade a sensações como realização, empoderamento, fortalecimento de autoestima.

Core drives Black Hat, por outro lado, podem gerar efeitos negativos ao associarem a dinâmica educativa a ansiedade, impaciência ou medo. É importante mencionar, no entanto, que nem sempre core drives desta natureza geram resultados negativos. Existem processos gamificados baseados em Black Hat core drives que motivam pessoas a praticar esportes ou a controlar a alimentação, o que claramente promove uma vida mais saudável (CHOU, 2014).

\subsubsection{Controle de conclusão e lista de atividades}

O controle de conclusão é uma funcionalidade nativa que pode ser habilitada ou desabilitada da plataforma Moodle. Ela indica o modo como a atividade será concluída automaticamente de acordo com critérios (visualização, nota, número de participações, data etc) ou marcada manualmente pelos participantes.

\subsubsection{Escolha eletrônica e enquetes}

O uso das enquetes e escolhas eletrônicas permite que as pessoas escolham o coletivamente os percursos e tenham seus interesses atendidos. Por exemplo, uma das atividades implementadas foi a enquete sobre escolha dos conflitos da humanidade para serem resolvidos em grupo. Assim, será aberto o fórum temático escolhido pelo grupo na enquete eletrônica.

Outra enquete usada foi o "positivômetro" para saber qual é a visão do participante sobre a solução de conflito logo após saber um pouco sobre a origem e as consequências dos conflitos.

\subsubsection{Níveis globais por pontuação e por grupos}

O curso foi segmentado em 5 níveis. Para alcançar cada nível o participante deve alcançar um certo número de pontos. A ideia foi conectar os níveis de pacificação com conceitos de paz. As atividades do curso que valem pontos devem ser cumpridas com seus critérios e os pontos são acumulados. Ao acumular pontos, é possível passar de nível. A pontuação pode ser contabilizada por grupo. A Figura 4 exemplifica a distribuição dessa pontuação. 
Figura 4 - Rótulos e distribuição dos pontos
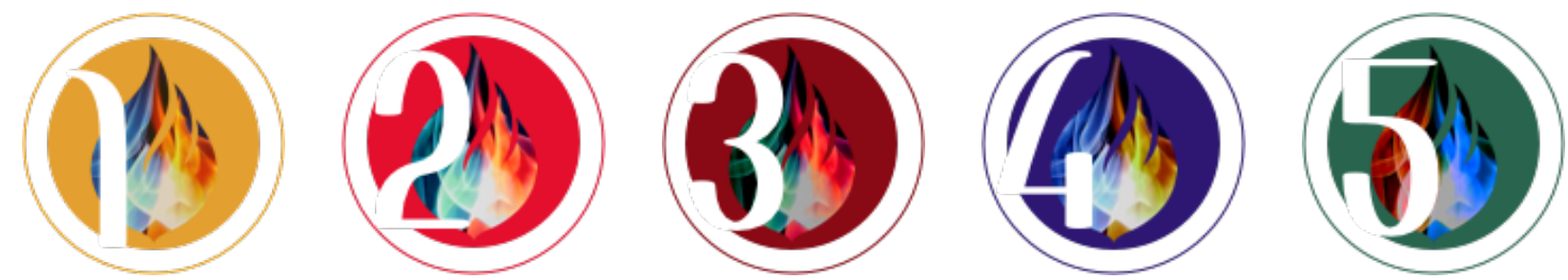

Principius

Humanus
100 pontos

\section{Yogis}

Mongis

Zenis

0 pontos

100 pontos

200 pontos

300 pontos

743 pontos

Fonte: o autor

\subsubsection{Acesso condicional e barra de progresso}

Em algumas atividades foi configurado o acesso condicional a atividades por critérios estabelecidos de acesso, grupo, pontos, emblemas etc. O acesso condicional é feito por configuração de parâmetros das atividades. Já a barra de progresso é uma interface que representa um checklist de atividades com um indicador de status (em andamento, concluído, não concluído).

\subsubsection{Emblemas ou Badges}

Os badges fazem conexão com o conteúdo relacionado a solução de conflitos. À medida que os participantes desenvolvem certas atividades, podem ganhar badges dos líderes mundiais da paz. Exemplos da utilização de badges e suas condições para aquisição são representados na Figura 5.

Figura 5-Badges e suas condições para aquisição

\begin{tabular}{|c|c|c|c|c|}
\hline Nome ${ }^{-}$ & Status do emblema & Critérios & Destinatários & Ações \\
\hline Pacificador & Disponivel para usuários & $\begin{array}{l}\text { Concluir QUALQUER de: "Fórum - Guerra civil e crise dos } \\
\text { refugiados sírios", "Fórum - Terrorismo e fundamentalismo } \\
\text { religioso", "Fórum - Tráfico de drogas e violência nas cidades", } \\
\text { "Fórum - Ameaças atômicas da Coreia do Norte" }\end{array}$ & 0 & ( ) \\
\hline bertador & Disponível para usuários & $\begin{array}{l}\text { Concluir QUALQUER de: "E-Voting - Qual conflito você gostaria } \\
\text { de resolver?", "Questionário - Mapa de sentimentos", "E-Voting - } \\
\text { Qual era o sentimento de Edmilson", "E-Voting - Qual era o } \\
\text { sentimento de Jandira", "Fórum - Fórum - Como você resolveria } \\
\text { o conflito entre Jandira e Edmilson" }\end{array}$ & 1 & - $\infty \propto$ \\
\hline uminador & $\begin{array}{c}\text { Não disponivel para os } \\
\text { usuários }\end{array}$ & $\begin{array}{l}\text { - Concluir o curso"A paz em nós"por } 30 \text { julho } 2017 \text { com nota } \\
\text { mínima de } 70\end{array}$ & 0 & (1) $\infty \boldsymbol{\theta}$ \\
\hline gregador & Disponivel para usuários & $\begin{array}{l}\text { - Concluir TUDO de: "URL - Tópico } 4 \text { - Conhecendo a questão | } \\
\text { informações", "URL - Tópico } 5 \text { - As questões por trás dos } \\
\text { conflitos", "URL - Tópico } 6 \text { - Controvérsias, soluções e } \\
\text { resoluções", "URL - Tópico } 7 \text { - Soluções e resoluções" }\end{array}$ & 0 & (1) $\infty \boldsymbol{\theta}$ \\
\hline opático & Disponível para usuários & $\begin{array}{l}\text { - Concluir TUDO de: "Quizventure - Elimine as palavras que } \\
\text { ferem", "Tarefa - Atividades de reflexão - Situação e solução de } \\
\text { desafios" }\end{array}$ & 0 & - $\infty \propto$ \\
\hline
\end{tabular}




\subsubsection{Conteúdo escondido Easter eggs}

Foram projetados alguns conteúdos escondidos. Esses conteúdos são cartas que correspondem aos emblemas. Essas cartas ficam escondida em textos ou outras atividades do curso e tem conteúdos adicionais, frases ou outros elementos lúdicos complementares ao conteúdo do curso (Figura 6).

Figura 6-Cartas correspondentes aos emblemas empregadas como easter eggs
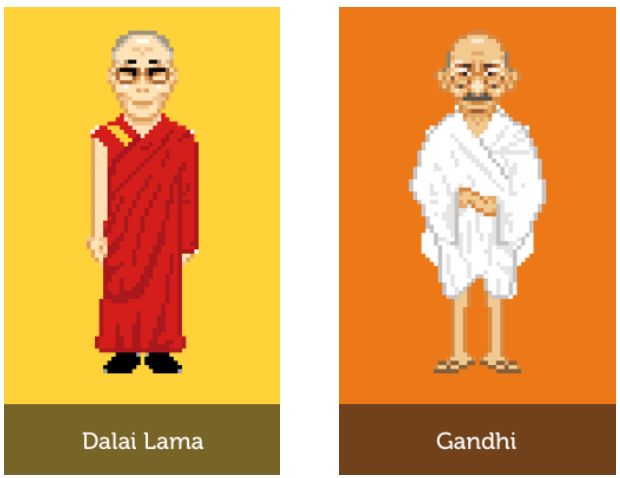
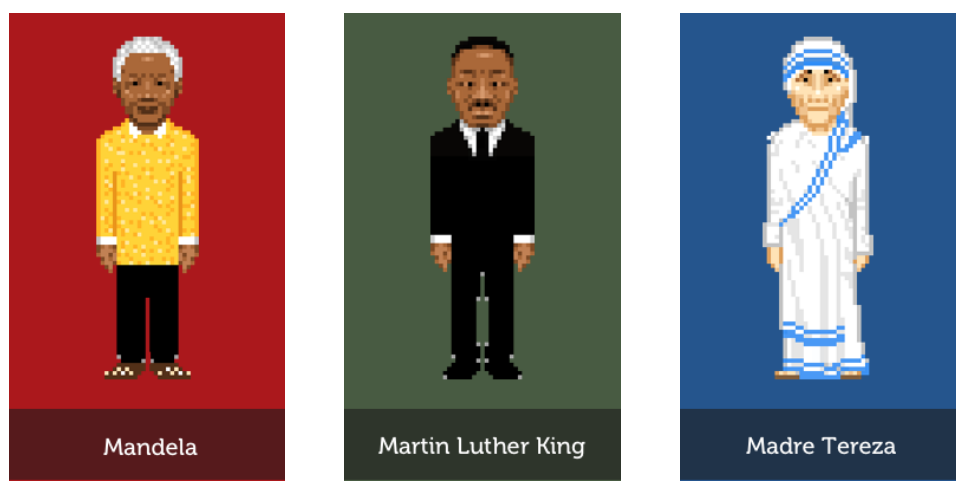

Fonte: o autor

\subsubsection{Quizventure}

O quizventure é um plug-in usado para gamificação de questões criando um ambiente tipo arcade game que lembra os jogos de Atari com pixerização das ilustrações. Foi criado um jogo de palavras, cuja missão é eliminar palavras nocivas que poderiam intensificar os conflitos (Figura 7).

Figura 7 - Jogo de eliminação de palavras

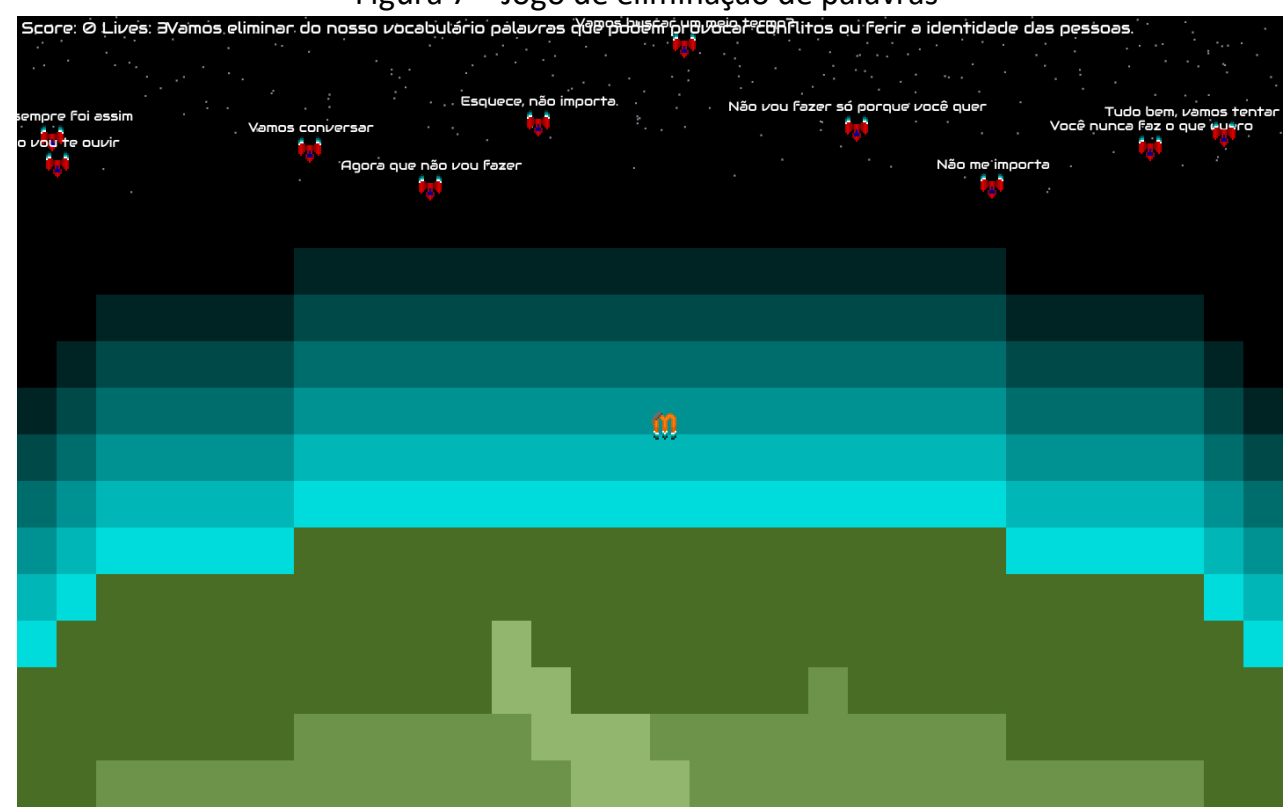

Fonte: o autor 


\section{Considerações}

O trabalho possibilitou o aprofundamento teórico e prático sobre o conceito de gamificação, o uso do framework Octalysis e também a reflexão sobre questões educacionais relacionadas às teorias abordadas na disciplina. Um desafio levantado, que inspirou empatia com o educador, foi o de pensar possibilidades de gamificação em ações educacionais online, em plataforma Moodle, porque é uma plataforma aberta, bastante difundida nos espaços formais de educação, em especial nas instituições públicas.

Foram enfrentadas lacunas da própria equipe ao longo do percurso, relacionadas à falta de experiência com gamificação. $E$, mergulhados entre perguntas, dúvidas e descobertas, os pesquisadores propuseram o percurso empático de tentar organizar algumas hipóteses de ferramentas e funcionalidades que podem ser aplicadas pelo educador na gamificação de cursos ofertados na plataforma Moodle.

Ainda, entende-se que há uma certa imprevisibilidade e um tempo útil dessas ferramentas, mas saber que existem possibilidades e que elas devem evoluir para se tornarem cada vez mais acessíveis, pode encorajar os educadores na construção de ações de aprendizagem mais lúdicas e engajadoras no contexto do mundo conectado.

Embora o propósito das ações educacionais devesse ser sempre o de promover o engajamento, apoiar o protagonismo e a autonomia, criando espaços interessantes e interativos nos quais a aprendizagem acontece de forma mais natural, este trabalho não pretendeu abordar essas questões diretamente. Nesse sentido, ainda estão abertas muitas das questões que foram vivenciadas e que são próprias das reflexões sobre o tema educação. Aqui o propósito foi o de olhar para uma metodologia pré-existente e deixar uma colaboração para futuros estudos, sem pretensões grandiosas, mas com os objetivos do compartilhamento e da colaboração, próprios dos educadores.

As técnicas, ferramentas e funcionalidades utilizados neste trabalho podem ser aplicados em diversos conteúdos, sobre diversos temas. Será sempre salutar a elaboração de um desenho educacional que inclua técnicas de gamificação, mas aplicado ao conteúdo (que é recomendável que já esteja elaborado) e aos objetivos de aprendizagem. Talvez um dos percursos de evolução deste trabalho seja o de olhar para o desenho educacional do ponto de vista da gamificação, tentando organizar um processo de desenho que permita a inclusão de atividades gamificadas.

Recomenda-se a finalização do conteúdo para verificação das demais sequências de atividades e a oferta curso a um grupo inicial de participantes para avaliação da jogabilidade e do engajamento dos estudantes. Os objetivos iniciais de inventariar, instalar e aplicar ferramentas e técnicas de gamificação em plataforma Moodle, sem uso de linguagens de programação, foram alcançados. E do trabalho, herdou-se uma bagagem rica em experiências e possibilidades que abriram novas perguntas, novos cenários e um outro universo a ser explorado.

\section{Referências}

BERBEL, N.A.N. As metodologias ativas e a promoção da autonomia de estudantes. 2011. Disponível em: <http://www.uel.br/revistas/uel/index.php/seminasoc/article/view/10326/ 10999>. Acesso em: 22 maio 2017.

CHOU, Y. Octalysis: Complete Gamification Framework. 2014. Disponível em: 
<www.yukaichou.com>. Acesso em: 19 maio 2017.

EBNER, Martin; HOLZINGER; Andreas. Successful implementation of user-centered game based learning in higher education: An example from civil engineering. Computers \& Education, vol. 49, pag. 873-890. Austria: 2007.

FARDO, M. L. A gamificação como estratégia pedagógica: estudo de elementos dos games aplicados em processos de ensino e aprendizagem / Marcelo Luis Fardo. 2013. Disponível em: <https://repositorio.ucs.br/xmlui/bitstream/handle/11338/457/Dissertacao\%20Marcelo\%20Luis\% 20Fardo.pdf?sequence=1\&isAllowed=y>. Acesso em: 20 maio 2017.

FRAGELLI, R. R. Jogos educativos como estratégia para aprendizagem ativa em cálculo: o par ou ímpar universitário e a apneia das funções trigonométricas inversas. Revista do Instituto Superior Tupy. n.13. 2012. Disponível em: <http://www.sociesc.org.br/download/?tipo=anx\&count=1\&id= 14344>. Acesso em: 4 abr. 2017.

FREIRE, Paulo. Pedagogia da autonomia: saberes necessários à prática educativa. São Paulo: Paz e Terra, 1996.

MORAN, J. Mudando a educação com metodologias ativas. 2015. Disponível em: <http://www2.eca.usp.br/moran/wp-content/uploads/2013/12/mudando_moran.pdf>. Acesso em: 19 maio 2017.

PRENSKY, M. Aprendizagem Baseada em Jogos Digitais. São Paulo: SENAC, 2012.

SILVA, T. B. P. Reflexões sobre game design: o planejamento e a experiência de jogo. In: SILVA, T. B. P.; SARMET, M. M.; SILVINO, A. M. D. Gameplay: ensaios sobre estudo e desenvolvimento de jogos. Equador: CIESPAL, 2016.

PREECE, Jennifer; ROGERS, Yvonne; SHARP, Helen. Design de interação: além da interação homem-computador. Porto Alegre, RS: Bookman, 2005.

VASSÃO, Caio Adorno. Metadesign: ferramentas, estratégias e ética para a complexidade. São Paulo: Blucher, 2010. 